Article

\title{
Influence of Quantum-Well Number and an AlN Electron Blocking Layer on the Electroluminescence Properties of AlGaN Deep Ultraviolet Light-Emitting Diodes
}

\author{
Shuxin Tan ${ }^{1}$, Jicai Zhang ${ }^{2,3, *}$, Takashi Egawa ${ }^{4, *}$ and Gang Chen ${ }^{3}$ \\ 1 School of Electronics and Information, Nantong University, 9 Seyuan Road, Nantong 226019, China; \\ tansx2014@ntu.edu.cn \\ 2 Department of Physics, College of Science, Beijing University of Chemical Technology, 15 East Road, \\ Beisanhuan, Beijing 100029, China \\ 3 Suzhou Institute of Nano-tech and Nano-bionics, CAS, 398 Ruoshui Road, SEID, SIP, Suzhou 215123, China; \\ Gangchen2016@sinano.ac.cn \\ 4 Research Center for Nano-Device and System, Nagoya Institute of Technology, Gokiso-cho, Showa-ku, \\ Nagoya 466-8555, Japan \\ * Correspondence: jczhang@mail.buct.edu.cn (J.Z.); egawa.takashi@nitech.ac.jp (T.E.); \\ Tel.: +86-10-64434899 (J.Z.); +81-52-7355544 (T.E.)
}

Received: 7 October 2018; Accepted: 23 November 2018; Published: 26 November 2018

\begin{abstract}
The influence of quantum-well (QW) number on electroluminescence properties was investigated and compared with that of AlN electron blocking layer (EBL) for deep ultraviolet light-emitting diodes (DUV-LEDs). By increasing the QW number, the band emission around $265 \mathrm{~nm}$ increased and the parasitic peak around $304 \mathrm{~nm}$ was suppressed. From the theoretical calculation, the electron current overflowing to the p-type layer was decreased as the QW number increased under the same injection. Correspondingly, the light output power also increased. The increment of output power from 5 QWs to 10 QWs was less than that from 10 QWs to 40 QWs, which was very different from what has been reported for blue and near-UV LEDs. The parasitic peak was still observed even when the QW number increased to 40. However, it can be suppressed efficiently by $1 \mathrm{~nm}$ AlN EBL for LEDs with 5 QWs. The simulation showed that the insertion of a thin EBL increased the barrier height for electron overflow and the electron current in p-type layers decreased significantly. The results contributed to the understanding of behavior of electron overflow in DUV-LEDs.
\end{abstract}

Keywords: deep ultraviolet light-emitting diodes; AlGaN; electroluminescence; electron overflow; electron blocking layer

\section{Introduction}

GaN and AlN alloys have attracted more and more attention as candidate materials for realizing ultraviolet (UV) optoelectronics [1-5]. As potential substitutes for the traditional mercury UV light source, AlGaN-based deep UV light-emitting diodes (DUV-LEDs) have attracted more and more attention due to their potential applications in many fields, such as solid-state lighting, medicine, and biochemistry. In the past few decades, the significant research efforts into the development of III-nitride UV LEDs have resulted in LED operation over a wide range of UV wavelengths from $210 \mathrm{~nm}$ to $400 \mathrm{~nm}$. Recently, Li et al. summarized the recent advances in UV materials and devices and gave guidance to further development and applications [1]. Nevertheless, the external quantum efficiency (EQE) of such a device decreased significantly as the wavelength decreased. Particularly when the wavelength was less than $300 \mathrm{~nm}$, the EQE and output power were far lower than those of 
their visible counterparts. There are several factors responsible for the lower EQE and power, such as the lack of high-quality AlN substrate or an AlGaN template with low threading dislocation density, the difficulty in obtaining high conductivity in p-type layers [6-8], and the excessive self-heating effect of these devices under direct current operation [2,3]. In addition, the large spontaneous and piezoelectric fields in group III nitrides will result in the tilted band structure diagrams of multiple quantum wells (MQWs) $[9,10]$ and reduce overlap of electron and hole wave functions, which will decrease the internal quantum efficiency of DUV-LEDs. Due to the lack of high-quality AlN substrate, a high-quality AlN template on sapphire is usually used for DUV-LEDs. It is well known that the weak surface migration of $\mathrm{Al}$ adatoms on the growth front limited the improvement of crystal quality. Therefore, many growth techniques have been developed for high quality AlN growth [11-15]. It has been demonstrated that high temperature annealing could significantly improve the AlN crystal quality [11]. By increasing the growth temperature, high-quality AlN thick films were obtained by homemade high temperature hydride vapor phase epitaxy [12]. Sun et al. revealed the mechanism of different initial conditions on the quality of AlN and got high quality AIN on sapphire substrate by a "two-step" method [13]. In addition, nano-patterned sapphire and AlN/sapphire templates were used for high-quality AlN growth $[14,15]$. As the crystal quality increased, the efficiency can be increased effectively [16]. Besides the increase in crystal quality, the use of core-shell-type AlGaN/AlN MQWs on AlN nanorods can also significantly increase the photoluminescent efficiency due to the decrease in dislocation density, the large active volume and the increase of light extraction efficiency [17]. In addition to the above-mentioned factors, electron overflow also exists in these devices. The electron overflow not only decreases the EQE and forward-voltage characteristics $[18,19]$, but also results in a sub-band parasitic peak $[20,21]$. Therefore, the suppression of electron overflow is absolutely favorable for the optical property of the devices. Generally, an electron blocking layer (EBL) between the active region and the p-type layers was used to suppress the electron overflow. There are seldom works to study the effect of quantum well (QW) number on the electron overflow in DUV-LEDs. It has been reported that with the increase in InGaN QW number from 5 to 7 , the external quantum efficiency (EQE) was increased by 30.4\% [22]. However, when the QW number increased to more than 15, the photoluminescence intensity of InGaN/GaN MQWs decreased significantly due to the relaxation of an accumulated strain through the dislocations induced by an increase in the total thickness of the MQWs [23]. In this work, we found that the electron overflow was partly suppressed and the relative output power continued to increase as the QW number increased up to 40.

\section{Experiment}

The LEDs were grown by metal-organic chemical vapor deposition on (0001)-sapphire substrate using a $1.0 \mu \mathrm{m}$ AlN buffer layer followed by a $0.5 \mu \mathrm{m}$ thick undoped $\mathrm{Al}_{0.6} \mathrm{Ga}_{0.4} \mathrm{~N}$ and a $1.0 \mu \mathrm{m}$ thick $\mathrm{n}-\mathrm{Al}_{0.6} \mathrm{Ga}_{0.4} \mathrm{~N}$ template. Then, $\mathrm{Al}_{0.49} \mathrm{Ga}_{0.51} \mathrm{~N} / \mathrm{Al}_{0.55} \mathrm{Ga}_{0.45} \mathrm{~N}$ MQWs were grown as active regions. The thicknesses of wells and barriers measured by transmission electron microscopy are $2.8 \mathrm{~nm}$ and $5.9 \mathrm{~nm}$, respectively. p- $\mathrm{Al}_{0.3} \mathrm{Ga}_{0.7} \mathrm{~N}(25 \mathrm{~nm}) / \mathrm{Al}_{0.6} \mathrm{Ga}_{0.4} \mathrm{~N}(25 \mathrm{~nm})$ were used as p-type layers. Finally, a $25 \mathrm{~nm}$ p-GaN contact layer was deposited. Based on the above structure, four samples were grown, and the different characteristics are listed in Table 1. LEDs A, B and C have 5, 10 and 40 period MQWs, respectively. LED D has a similar structure to LED A, except that it has a $1 \mathrm{~nm}$ thick i-AlN interlayer between the active region and the p-type layers. A $500 \mu \mathrm{m} \times 500 \mu \mathrm{m}$ square geometry $\mathrm{p}-\mathrm{n}$ junction device was fabricated using standard lithographic techniques to define the feature and reactive ion etching (RIE) was used to expose the $\mathrm{n}-\mathrm{Al}_{0.6} \mathrm{Ga}_{0.4} \mathrm{~N}$ Ohmic contact layer. n-type Ohmic contacts of Ti/Al/Ni/Au $(15 \mathrm{~nm} / 80 \mathrm{~nm} / 12 \mathrm{~nm} / 60 \mathrm{~nm})$ were deposited by electron beam evaporation and annealed with a rapid thermal annealing system at $900{ }^{\circ} \mathrm{C}$ for $30 \mathrm{~s}$ in nitrogen ambience. For transparent p-contacts, $\mathrm{Ni} / \mathrm{Au}(6 \mathrm{~nm} / 12 \mathrm{~nm})$ layers were electron beam deposited and annealed in air ambience at $600{ }^{\circ} \mathrm{C}$ for $3 \mathrm{~min}$. The device was completed with the deposition of a Ni/Au $(5 \mathrm{~nm} / 60 \mathrm{~nm}) \mathrm{p}$ contact. Figure $1 \mathrm{a}-\mathrm{p}$ shows the flow chart of the device process in order, in which Figure $1 \mathrm{a}, \mathrm{e}, \mathrm{i}, \mathrm{m}$ show the spinning coating, Figure $1 \mathrm{~b}, \mathrm{f}, \mathrm{j}, \mathrm{n}$ show the lithographic process, 
Figure 1c shows the RIE; Figure 1d,h,l,p show the glue cleaning; and Figure 1g,k,o show the electron beam evaporation of metals. The electroluminescent (EL) spectrum was measured at room temperature using a HORIBA Jobin Yvon's Symphony UV-enhanced liquid nitrogen-cooled charge-coupled device detector. Agilent $4156 \mathrm{C}$ was used as the current source.

Table 1. The quantum-well (QW) numbers and electron blocking layer (EBL) structures for all the deep UV light-emitting diodes (DUV-LEDs) used in this work.

\begin{tabular}{ccc}
\hline LEDs & EBL & QW Number \\
\hline A & no & 5 \\
B & no & 10 \\
C & no & 40 \\
D & 1 nm AlN & 5 \\
\hline
\end{tabular}

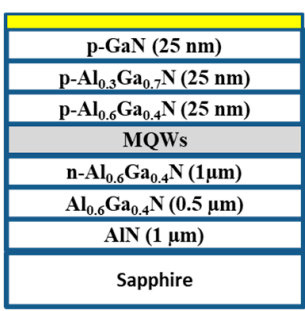

a

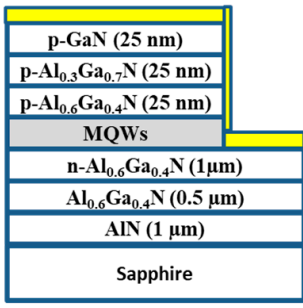

e

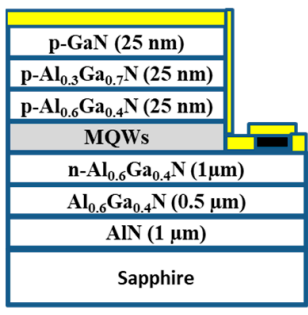

i

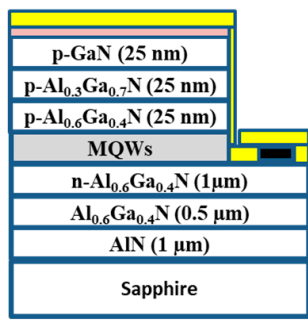

m

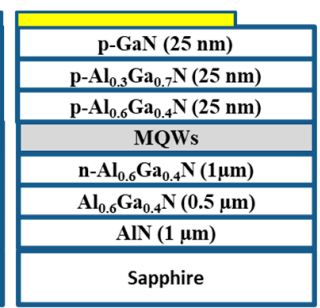

b

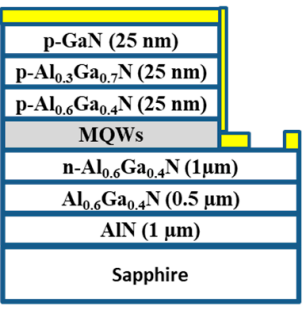

f

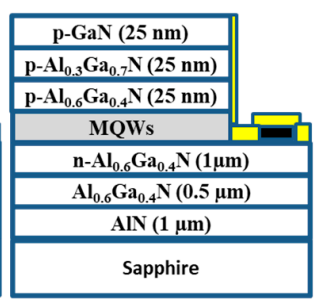

j

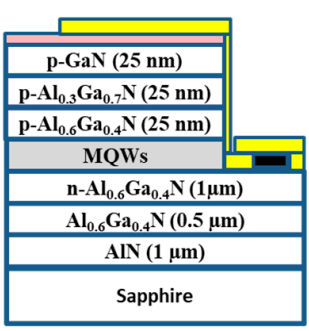

n

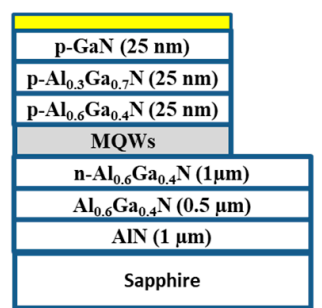

C

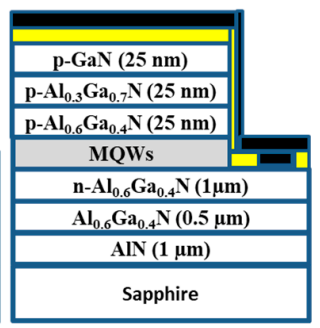

g

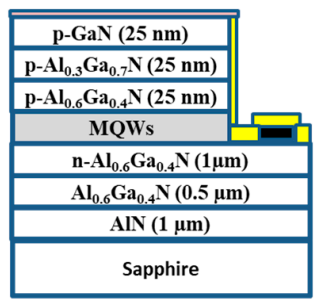

k

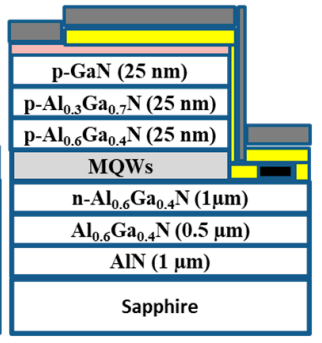

o

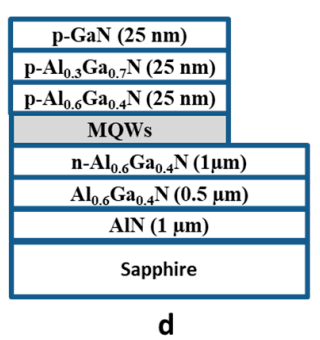

d

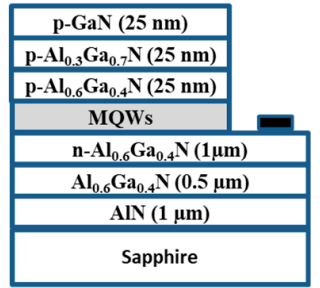

h

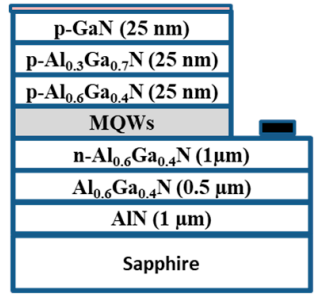

I

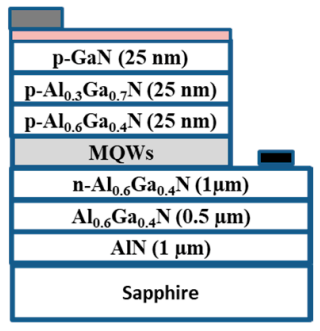

p

Figure 1. The flow chart of the device process. $(\mathbf{a}, \mathbf{e}, \mathbf{i}, \mathbf{m})$ show the spinning coating. $(\mathbf{b}, \mathbf{f}, \mathbf{j}, \mathbf{n})$ show the lithographic process. (c) shows the RIE. $(\mathbf{d}, \mathbf{h}, \mathbf{l}, \mathbf{p})$ show the glue cleaning. $(\mathbf{g}, \mathbf{k}, \mathbf{o})$ show the electron beam evaporation of metals. 


\section{Experimental Results}

Figure 2a shows the EL spectra for LEDs A, B and C under direct current of $40 \mathrm{~mA}$, in which all the spectra were normalized to the band-to-band emission. The slightly different wavelengths of band-to-band emissions between LED A and the other devices was probably due to the flux deviation during the growth of quantum wells. A parasitic peak around $304 \mathrm{~nm}$ besides the band-to-band emission can be observed for all the LEDs. The parasitic peak has been clarified to be related to the electron overflow and $\mathrm{Mg}$ doping concentration in the p-AlGaN cladding layer [20]. As the QW number increased, the intensity of the parasitic peak decreased, which meant the electron overflow decreased. Figure $2 b$ shows the intensity ratio of the band-to-band emissions to the parasitic peaks for all devices at different direct current injections. The ratio increased as the current increased, indicating more and more carriers were involved in the band-to-band radiative recombination. For the same injection current, the ratio increased as the QW number increased, which meant that the ratio of carrier recombination inside and outside the wells was increased.

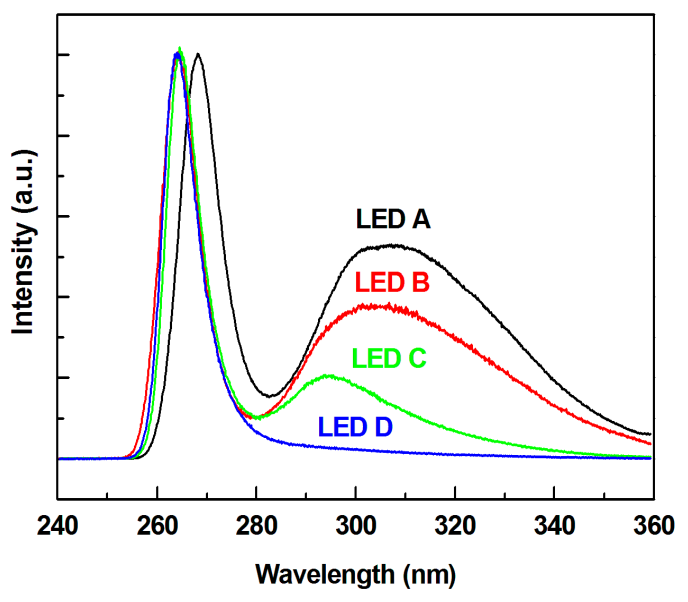

(a)

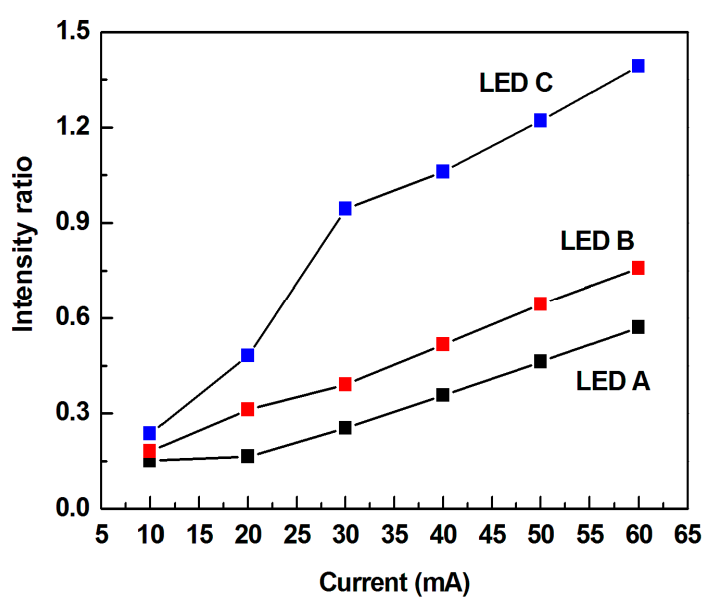

(b)

Figure 2. (a) The electroluminescent (EL) spectra for LEDs A, B, C and D under direct current of $40 \mathrm{~mA}$; (b) the intensity ratio of the band-to-band emissions to the parasitic peaks for LEDs A, B and C at different current. All the spectra were normalized to the band-to-band emission.

The relative output powers at different injections were obtained from the EL measurement. To avoid the influence of the thermal heating effect [3], the pulse injection with $1 \mu$ s current pulse at $0.5 \%$ was used in the EL measurements. Figure 3 shows the pulse injection dependent relative output power for all three devices. Obviously, the relative output power increased as the current increased. For a certain injection, the relative output power increased as the QW number increased, which indicated that the carriers captured by quantum wells increased with the increase in QW number. The increment of relative output power from 5 QWs to 10 QWs was less than that from 10 QWs to 40 QWs. For example, the output power ratios of LED B to LED A and LED C to LED B were 1.6 and 3.0 , respectively, at injection of $100 \mathrm{~mA}$. This phenomenon was very different from what has been reported for blue and near-UV LEDs [24], in which the carriers were exhausted mostly in the first ten QWs. The results indicated that the increase of QW number was favorable for the optical properties.

The influence of the EBL with different structures on the EL properties of DUV-LEDs has been investigated by many groups [25-28]. Generally, we used $1 \mathrm{~nm}$ i-AlN as an EBL to suppress the electron overflow [20]. For comparison in this work, DUV-LEDs with a $1 \mathrm{~nm}$ AlN EBL was grown for five period QWs, named LED D. The EL spectrum and the relative output power were shown in Figures 2a and 3, respectively. Obviously, the suppression efficiency of electron overflow in LED $\mathrm{D}$ was better than in LED A. Furthermore, LED D showed advanced property compared to LED C. Correspondingly, the relative output power was increased significantly for LED D. 


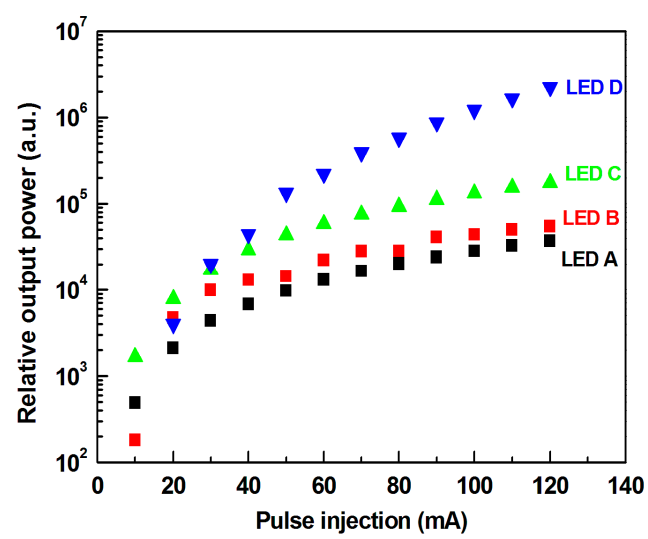

Figure 3. The pulse current dependent relative output power for LEDs A, B, C and D.

\section{Simulation and Discussion}

To understand the experimental results, an Advanced Physical Model of Semiconductor Devices (APSYS) simulation program was used to simulate the electron current distributions and the band structures. In order to get the change rule and avoid the complication of simulation, 3 QWs, 5 QWs, 10 QWs and 15 QWs, and a $1 \mathrm{~nm} \mathrm{Al}{ }_{0.92} \mathrm{Ga}_{0.08} \mathrm{~N}$ EBL were chosen. Tables 2 and 3 list the electron and hole concentrations and the thicknesses for different layers used in the simulation, respectively. Figure 4 shows the electron current distribution under an injection current of $120 \mathrm{~mA}$. It can be seen that the electron current overflowing to p-type layers decreased as the QW number increased. More and more carriers were exhausted in the active region as the QW number increased, which was believed to result in the decrease of the parasitic peak intensity as shown in Figure 2 and the increase of output power as shown in Figure 3. The localized state due to the fluctuation of the In composition is generally referred to be the dominant emission mechanism in InGaN QWs. Nevertheless, the radiative recombination from QWs was the dominant emission mechanism in AlGaN QWs. The increase in QW number will result in the increase of radiative recombination centers for both cases. However, the total thickness of the epilayer increased as the QW number increased, which would lead to the strain relaxation. It was well known that the localized states (due to the fluctuation of In composition in InGaN QWs) mainly resulted from the strain state. Therefore, the relaxation of strain influenced the optical properties of InGaN QWs. However, in AlGaN QWs, the strain state only has influence on the polarization field and the relaxation of the strain (mainly the tensile strain) can decrease the field, which contributes to the improvement of emission from AlGaN QWs. Therefore, in this work, as the QW number increased to 40 , the EL intensity still continued to increase.

Table 2. The electron and hole concentrations used in the simulation.

\begin{tabular}{ccc}
\hline Layers & Electron Concentration $\left(\mathrm{cm}^{-3}\right)$ & Hole Concentration $\left(\mathbf{c m}^{-3}\right)$ \\
\hline $\mathrm{p}-\mathrm{GaN}$ & & $5 \times 10^{18}$ \\
$\mathrm{p}-\mathrm{Al}_{0.3} \mathrm{Ga}_{0.7} \mathrm{~N}$ & $5 \times 10^{18}$ & $5 \times 10^{17}$ \\
$\mathrm{p}-\mathrm{Al}_{0.6} \mathrm{Ga}_{0.4} \mathrm{~N}$ & $5 \times 10^{17}$ \\
$\mathrm{n}-\mathrm{Al}_{0.6} \mathrm{Ga}_{0.4} \mathrm{~N}$ & 5 & \\
\hline
\end{tabular}

However, for the same QW number, the LED with a $1 \mathrm{~nm} \mathrm{Al} \mathrm{Al}_{0.92} \mathrm{Ga}_{0.08} \mathrm{~N}$ EBL showed a far lower electron current overflow than those without EBL. To understand the phenomenon, the band structures for both LEDs were simulated. Figure $5 \mathrm{a}, \mathrm{b}$ shows the band structures of LEDs with and without a $1 \mathrm{~nm} \mathrm{Al}{ }_{0.92} \mathrm{Ga}_{0.08} \mathrm{~N}$ EBL under an injection current of $120 \mathrm{~mA}$, respectively. The barrier height for electron overflow in the LED without EBL was $0.255 \mathrm{eV}$. The insertion of the EBL resulted in a higher barrier height of $0.302 \mathrm{eV}$, which decreased the electron current overflowing to the p-type layers. It was believed that the use of AlN as an EBL would increase the barrier height further. The band structures 
of LEDs with 3 QWs, 10 QWs and 15 QWs are shown in Figure 6a-c, respectively. It can be seen that the barrier heights for electron overflow under the same injection for different numbers of QWs were almost the same, which indicated that the decrease of electron overflow with increasing QW number was just due to the increase in volume of the active region.

Table 3. The thicknesses for different layers used in the simulation.

\begin{tabular}{cc}
\hline Layers & Thickness (nm) \\
\hline $\mathrm{p}-\mathrm{GaN}_{\mathrm{p}-\mathrm{Al}_{0.3} \mathrm{Ga}_{0.7} \mathrm{~N}}$ & 25 \\
$\mathrm{p}-\mathrm{Al}_{0.6} \mathrm{Ga}_{0.4} \mathrm{~N}$ & 25 \\
$\mathrm{i}-\mathrm{Al}_{0.92} \mathrm{Ga}_{0.08} \mathrm{~N}$ & 25 \\
Well & 1 \\
Barrier $_{\mathrm{n}-\mathrm{Al}_{0.6} \mathrm{Ga}_{0.4} \mathrm{~N}}$ & 3 \\
\end{tabular}

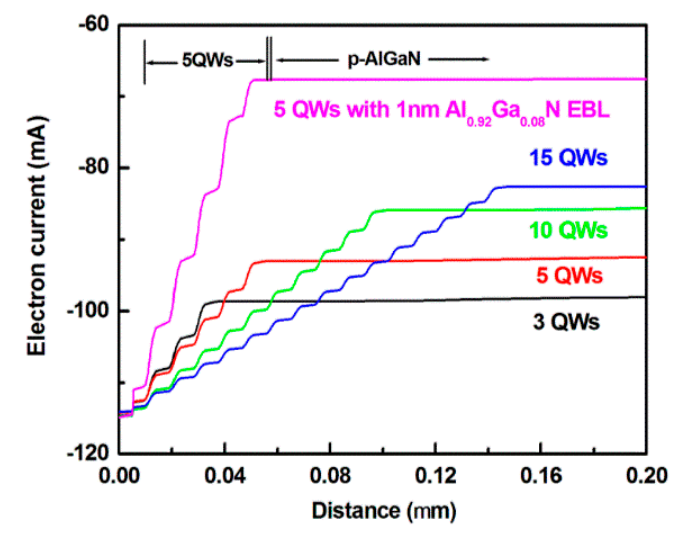

Figure 4. The electron current distribution under an injection current of $120 \mathrm{~mA}$ for LEDs with 3 QWs, 5 QWs, 10 QWs and 15 QWs and the 5 QW LED with a $1 \mathrm{~nm} \mathrm{Al}_{0.92} \mathrm{Ga}_{0.08} \mathrm{~N}$ EBL. The labels at the top of the graph refer to the different layers in the LED with $5 \mathrm{QWs}$ and a $1 \mathrm{~nm} \mathrm{Al}_{0.92} \mathrm{Ga}_{0.08} \mathrm{~N}$ EBL.

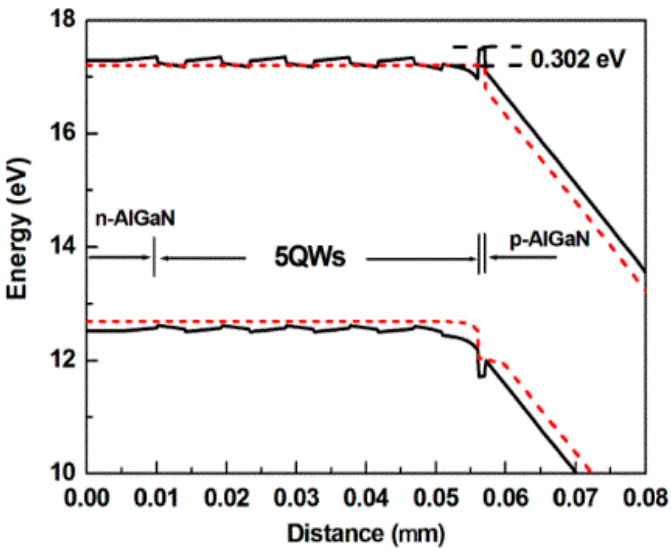

(a)

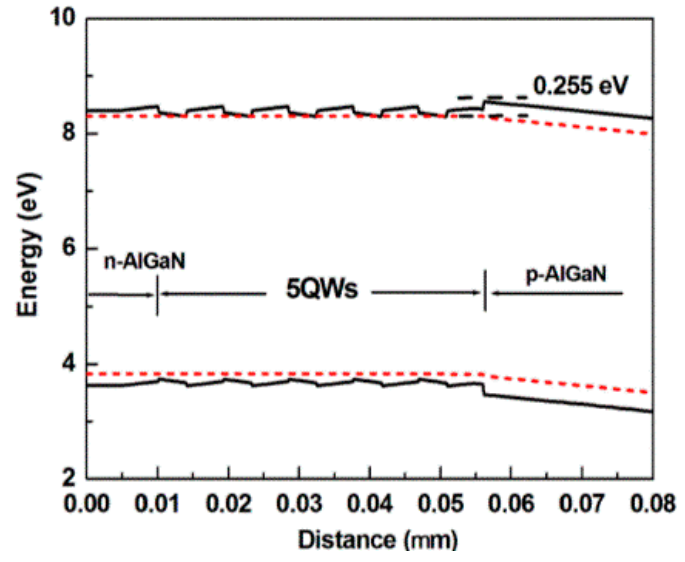

(b)

Figure 5. The band structures of LEDs (a) with and (b) without a $1 \mathrm{~nm} \mathrm{Al}_{0.92} \mathrm{Ga}_{0.08} \mathrm{~N}$ EBL under an injection current of $120 \mathrm{~mA}$. 


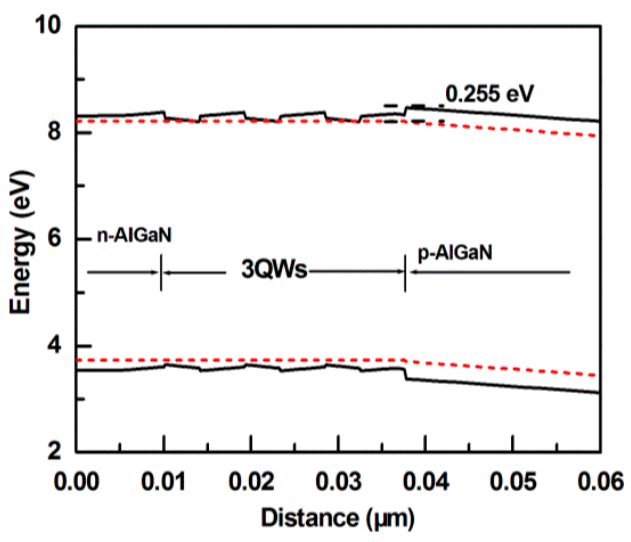

(a)

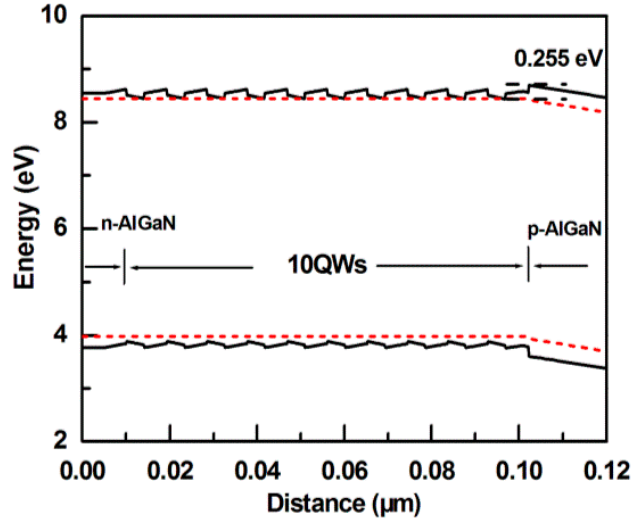

(b)

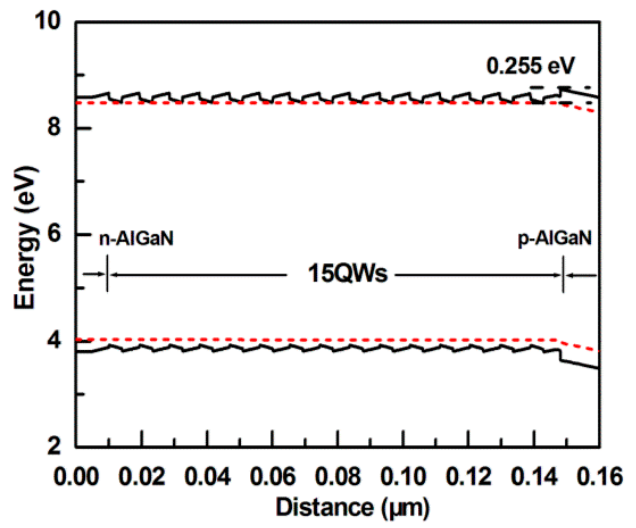

(c)

Figure 6. The band structures of LEDs with (a) 3 QWs; (b) 10 QWs and (c) 15 QWs without an EBL under an injection current of $120 \mathrm{~mA}$.

\section{Conclusions}

We studied the effect of QW number on EL properties in AlGaN-based DUV-LEDs. An increase in QW number could decrease the electron current overflow, which resulted in the improvement of band emission around $265 \mathrm{~nm}$ and a decrease in the parasitic peak around $304 \mathrm{~nm}$. As a result, the light output power was increased. However, the increment of output power from 5 QWs to 10 QWs was less than that from $10 \mathrm{QWs}$ to $40 \mathrm{QWs}$, which was very different from what has been reported for blue and near-UV LEDs. From the comparison of LEDs with and without a $1 \mathrm{~nm}$ AlN EBL for the same QW numbers, we could conclude that the efficiency of the EBL was better than that of the QW-number increase for suppressing the electron current overflow. The simulation showed that the use of a thin EBL increased the barrier height for electron overflow and significantly decreased the electron current in p-type layers.

Author Contributions: Writing-Original draft preparation with analysis, S.T.; APSYS simulation, G.C.; Experiment and writing—review, J.Z.; Supervision and writing—review, T.E.

Funding: This research received no external funding.

Acknowledgments: This work was partly supported by the National Natural Science Foundation of China (No. 61474133, 61504071), Beijing Municipal Natural Science Foundation (4182046), and the research project of Beijing University of Chemical Technology (YY1701, buctrc201802).

Conflicts of Interest: The authors declare no conflict of interest. 


\section{References}

1. Li, D.; Jiang, K.; Sun, X.; Guo, C. AlGaN photonics: Recent advances in materials and ultraviolet device. Adv. Opt. Photonics 2018, 10, 43-110. [CrossRef]

2. Chitnis, A.; Sun, J.; Mandavilli, V.; Pachipulusu, R.; Wu, S.; Gaevski, M.; Adivarahan, V.; Zhang, J.P.; Khan, M.A.; Sarua, A.; et al. Self-heating effects at high pump currents in deep ultraviolet light-emitting diodes at $324 \mathrm{~nm}$. Appl. Phys. Lett. 2002, 81, 3491-3493. [CrossRef]

3. Zhang, J.C.; Zhu, Y.H.; Egawa, T.; Sumiya, S.; Miyoshi, M.; Tanaka, M. Influence of pulse width on electroluminescence and junction temperature of AlInGaN deep ultraviolet light-emitting diodes. Appl. Phys. Lett. 2008, 92, 191917. [CrossRef]

4. Du, C.; Jing, L.; Jiang, C.; Liu, T.; Pu, X.; Sun, J.; Li, D.; Hu, W. An effective approach to alleviating the thermal effect in microstripe array-LEDs via the piezo-phototronic effect. Mater. Horiz. 2018, 5, 116-122. [CrossRef]

5. Li, D.; Sun, X.; Song, H.; Li, Z.; Chen, Y.; Jiang, H.; Miao, G. Realization of a High-Performance GaN UV Detector by Nanoplasmonic Enhancement. Adv. Mater. 2012, 24, 845-849. [CrossRef] [PubMed]

6. Nakarmi, M.L.; Kim, K.H.; Khizar, M.; Fan, Z.Y.; Lin, J.Y.; Jiang, H.X. Electrical and optical properties of Mg-doped $\mathrm{Al}_{0.7} \mathrm{Ga}_{0.3} \mathrm{~N}$ alloys. Appl. Phys. Lett. 2005, 86, 092108. [CrossRef]

7. Kinoshita, T.; Obata, T.; Yanagi, H.; Inoue, S. High p-type conduction in high-Al content Mg-doped AlGaN. Appl. Phys. Lett. 2013, 102, 012105. [CrossRef]

8. Kim, H.K.; Seong, T.Y.; Adesida, I.; Tang, C.W.; Lau, K.M. Low-resistance Pt/Pd/Au ohmic contacts to p-type AlGaN. Appl. Phys. Lett. 2004, 84, 1710-1712. [CrossRef]

9. Huang, X.; Du, C.; Zhou, Y.; Jiang, C.; Pu, X.; Liu, W.; Hu, W.; Chen, H.; Wang, Z.L. Piezo-Phototronic Effect in a Quantum Well Structure. ACS Nano 2016, 10, 5145-5152. [CrossRef]

10. Yang, G.F.; Xie, F.; Dong, K.X.; Chen, P.; Xue, J.J.; Zhi, T.; Tao, T.; Liu, B.; Xie, Z.L.; Xiu, X.Q.; et al. Design of deep ultraviolet light-emitting diodes with staggered AlGaN quantum wells. Phys. E Low-Dimens. Syst. Nanostruct. 2014, 62, 55-58. [CrossRef]

11. Miyake, H.; Lin, C.-H.; Tokoro, K.; Hiramatsu, K. Preparation of high-quality AlN on sapphire by high-temperature face-to-face annealing. J. Cryst. Growth 2016, 456, 155-159. [CrossRef]

12. Sun, M.; Zhang, J.; Huang, J.; Li, X.; Wang, L.; Liu, X.; Wang, J.; Xu, K. Influence of thickness on strain state and surface morphology of AlN grown byHVPE. J. Semicond. 2016, 37, 123001. [CrossRef]

13. Sun, X.; Li, D.; Chen, Y.; Song, H.; Jiang, H.; Li, Z.; Miao, G.; Zhang, Z. In situ observation of two-step growth of AlN onsapphire using high-temperature metal-organic chemical vapour deposition. CrystEngComm 2013, 15, 6066-6073. [CrossRef]

14. Jiang, K.; Sun, X.; Ben, J.; Jia, Y.; Liu, H.; Wang, Y.; Wu, Y.; Kai, C.; Li, D. The defect evolution in homoepitaxial AlN layers grown by high-temperature metal-organic chemical vapor deposition. CrystEngComm 2018, 20, 2720-2728. [CrossRef]

15. Zhang, L.; Xu, F.; Wang, J.; He, C.; Guo, W.; Wang, M.; Sheng, B.; Lu, L.; Qin, Z.; Wang, X.; et al. High-quality AlN epitaxy on nano-patterned sapphire substrates prepared by nano-imprint lithography. Sci. Rep. 2016, 6, 35934. [CrossRef] [PubMed]

16. Nagasawa, Y.; Hirano, A. A Review of AlGaN-Based Deep-Ultravioletht-Emitting Diodes on Sapphire. Appl. Sci. 2018, 8, 1264. [CrossRef]

17. Kim, J.; Choi, U.; Pyeon, J.; So, B.; Nam, O. Deep-Ultraviolet AlGaN/AlN Core-Shell Multiple Quantum Wells on AlN Nanorods via Lithography-Free Method. Sci. Rep. 2018, 8, 935. [CrossRef]

18. Kuo, Y.-K.; Chang, Y.-A. Effects of electronic current overflow and inhomogeneous carrier distribution on InGaN quantum-well laser performance. IEEE J. Quantum Electron. 2004, 40, 437-444.

19. Han, D.-P.; Kim, H.; Shim, J.-I.; Shin, D.-S.; Kim, K.-S. Influence of carrier overflow on the forward-voltage characteristics of InGaN-based light-emitting diodes. Appl. Phys. Lett. 2014, 105, 191114. [CrossRef]

20. Zhang, J.C.; Zhu, Y.H.; Egawa, T.; Sumiya, S.; Miyoshi, M.; Tanaka, M. Suppression of the subband parasitic peak by $1 \mathrm{~nm}$ i-AlN interlayer in AlGaN deep ultraviolet light-emitting diodes. Appl. Phys. Lett. 2008, 93, 131117. [CrossRef]

21. Fischer, A.J.; Allerman, A.A.; Crawford, M.H.; Bogart, K.H.A.; Lee, S.R.; Kaplar, R.J.; Chow, W.W.; Kurtz, S.R.; Fullmer, K.W.; Figiel, J.J. Room-temperature direct current operation of $290 \mathrm{~nm}$ light-emitting diodes with milliwatt power levels. Appl. Phys. Lett. 2004, 84, 3394-3396. [CrossRef] 
22. Choi, H.-S.; Zheng, D.-G.; Kim, H.; Shim, J.-I.; Shin, D.-S. Effects of the number of quantum wells on the performance of near-ultraviolet light-emitting diodes. J. Korean Phys. Soc. 2015, 66, 1554-1558. [CrossRef]

23. Kim, D.-J.; Moon, Y.-T.; Song, K.-M.; Choi, C.-J.; Ok, Y.-W.; Seong, T.Y.; Park, S.-J. Structural and optical properties of InGaN/GaN multiple quantum wells: The e!ect of the number of InGaN/GaN pairs. J. Cryst. Growth 2000, 221, 368-372. [CrossRef]

24. Pan, C.-C.; Lee, C.-M.; Liu, J.-W.; Chen, G.-T.; Chyi, J.-I. Luminescence efficiency of InGaN multiple-quantum-well ultraviolet light-emitting diodes. Appl. Phys. Lett. 2004, 4, 5249-5251. [CrossRef]

25. Kolbe, T.; Stellmach, J.; Mehnke, F.; Rothe, M.A.; Kueller, V.; Knauer, A.; Einfeldt, S.; Wernicke, T.; Weyers, M.; Kneissl, M. Efficient carrier-injection and electron-confinement in UV-B light-emitting diodes. Phys. Status Solidi A 2016, 213, 210-214. [CrossRef]

26. So, B.; Kim, J.; Shin, E.; Kwak, T.; Kim, T.; Nam, O. Efficiency Improvement of Deep-Ultraviolet Light Emitting Diodes with Gradient Electron Blocking Layers. Phys. Status Solidi A 2018, 215, 1700677. [CrossRef]

27. Hirayama, H.; Tsukada, Y.; Maeda, T.; Kamata, N. Marked Enhancement in the Efficiency of Deep-Ultraviolet AlGaN Light-Emitting Diodes by Using a Multiquantum-Barrier Electron Blocking Layer. Appl. Phys. Express 2010, 3, 031002. [CrossRef]

28. Lu, L.; Ding, G.G.; Zhang, Y.; Liu, Y.H.; Xu, F.J. Improved Performance of AlGaN-Based Deep-Ultraviolet Light-Emitting Diodes using modulated-taper design for p-AlGaN layer. Semicond. Sci. Technol. 2018, 33, 0350008. [CrossRef]

(C) 2018 by the authors. Licensee MDPI, Basel, Switzerland. This article is an open access article distributed under the terms and conditions of the Creative Commons Attribution (CC BY) license (http:/ / creativecommons.org/licenses/by/4.0/). 